\title{
Paciente que Requer Cuidados Paliativos: Percepção de Enfermeiras
}

Gonçalves, Naiane Glaciele da Costa; Silveira, Rosemary Silva da; Holz, Jaqueline; Lunardi, Valéria Lerch; Silveira, Ana Caroline Silva da; Saioron, Isabela; Gonçalves, Naiane Glaciele da C.

Universidade Federal do Rio Grande — naianeglaciele@gmail.com

Introdução: a origem dos Cuidados Paliativos está no Movimento Hóspice, criado por Cecily Saunders e colaboradores, responsáveis pela disseminação em nível mundial dessa filosofia do cuidar. Objetivo: conhecer a percepção de enfermeiras de uma Unidade de Clínica Médica (UCM) sobre os cuidados paliativos. Metodologia: Pesquisa qualitativa desenvolvida com oito enfermeiras de uma UCM, de um hospital público federal, no sul do país. Utilizou-se a entrevista semiestruturada e a análise textual discursiva, desenvolvida em quatro focos: "Desmontagem dos textos", "Estabelecimento de relações", "Captando o novo emergente", "um processo auto organizado". Resultados: Emergiram duas categorias: percepções de enfermeiras acerca dos cuidados paliativos e o modo como as enfermeiras exercem seu fazer diante da impossibilidade de cura. Discussões: em relação às percepções das enfermeiras acerca dos cuidados paliativos podese perceber que há opiniões distintas, parecendo não existir clareza acerca de seu significado. Algumas enfermeiras explicitaram sua compreensão sobre cuidado paliativo como a possibilidade de realizar um cuidado ético, respeitando a integridade e dignidade dos pacientes. o discurso dos sujeitos demonstra a insuficiência de conhecimento acerca da temática cuidados paliativos nos processos formativos dos estudantes durante a graduação e nas atividades de educação permanente dos profissionais, refletindo a falta de clareza desta filosofia de cuidado. no que se refere ao modo como os enfermeiros exercem seu fazer diante da impossibilidade de cura, destacaram que além de promover o alívio da dor é necessário comprometer-se emocionalmente com os pacientes, respeitando sua vulnerabilidade. para o enfrentamento do sofrimento dos pacientes e de si próprios diante da dor e da impossibilidade de cura, os enfermeiros criam mecanismos de defesa pessoal, os quais Ihes permitem enfrentar as dificuldades presentes no diaa-dia de trabalho e cuidar do próximo sem se abalar. Pode-se perceber, a partir dos relatos dessas enfermeiras, que a experiência adquirida com o tempo, a maturidade pessoal e o enfrentamento do dia-a-dia no trabalho geram sentimentos de superação nas ações de cuidado, e que o sentimento que aflora é de respeito. É fundamental compartilhar vivências e experiências no contexto profissional dos trabalhadores entre si, com pacientes e familiares, produzindo maturidade para enfrentar o dia-a-dia no trabalho diante dos cuidados paliativos. Conclusões: Percebeu-se que existe uma dificuldade em desempenhar os cuidados paliativos devido à carência de conhecimento do tema por parte dos trabalhadores envolvidos no cuidado e à estrutura institucional, que não é direcionada para cuidados paliativos. Encontrar alternativas que estimulem discussões acerca dos cuidados paliativos poderá colaborar para suprir as dificuldades diante de pacientes que requerem cuidados paliativos.

Gonçalves, Naiane Glaciele da Costa; Silveira, Rosemary Silva da; Holz, Jaqueline; Lunardi, Valéria Lerch; Silveira, Ana Caroline Silva da; Saioron, Isabela; Gonçalves, Naiane Glaciele da C.. Paciente que Requer Cuidados Paliativos: Percepção de Enfermeiras. In: Anais do Congresso Internacional de Humanidades \& Humanização em Saúde [= Blucher Medical Proceedings, num.2, vol.1]. São Paulo: Editora Blucher, 2014. ISSN 2357-7282 DOI 10.5151/medpro-cihhs-10666 